\title{
FLUÊNCIA TECNOLÓGICA DOS TUTORES EM AMBIENTES VIRTUAIS
}

Elena Maria Mallmann - UFSM - elena.ufsm@gmail.com Daniele da Rocha Schneider - UFSM - dani.qmc@gmail.com Tatiana Gloor Teixeira - UFSM - tatianagteixeira@gmail.com Juliana Viero Sales - UFSM - juletras.jacques@ gmail.com Iris Cristina Datsch Toebe - UFSM - iristoebe@gmail.com

\begin{abstract}
Resumo: A fluência tecnológica dos tutores em ambientes virtuais implica saber como utilizar as tecnologias educacionais, compreendê-las, além de criar e compartilhar soluções. Pesquisamos de que modo os tutores utilizam e compreendem as ferramentas recursos (disponibilização de conteúdos) e atividades de aprendizagem para potencializar a mediação pedagógica em ambientes virtuais. Desenvolvemos observação participante e aplicamos um questionário tipo survey aos tutores presenciais e a distância, com foco na fluência em tecnologias educacionais. Analisamos os resultados de pesquisa-ação, destacando que a fluência tecnológica apresenta relação direta com a implementação das atribuições dos tutores, potencializando as situações de ensinoaprendizagem e a problematização em torno do conteúdo curricular. Concluímos afirmando que a fluência tecnológica dos tutores em ambientes virtuais requer habilidades contemporâneas, conceitos fundamentais e capacidades intelectuais para utilizar, compreender, criar e compartilhar soluções educacionais mediadas pelas tecnologias.
\end{abstract}

Palavras-chave: fluência tecnológica, tutores, ambientes virtuais.

\section{TECHNOLOGICAL FLUENCY OF THE TUTORS IN VIRTUAL ENVIRONMENTS}

\begin{abstract}
The technological fluency of the tutors in virtual environments requires knowing how to utilize and comprehend the available tools, in addition to creating and sharing solutions with the educational technologies. We investigated how the tutors utilize and comprehend the resource tools (availability of contents) and the learning activities in order to maximize the pedagogical mediation in virtual environments. We used participant observations and issued a survey questionnaire, focused on the educational tools fluency, to the face-to-face and in distance tutors. The results of the action research were analyzed highlighting that the technological fluency presents a direct relation to the implementation of the tutors' assignments, boosting the teachinglearning situations and the problematization regarding the curricular content. We concluded by stating that the tutors' technological fluency in virtual environments requires contemporary skills, fundamental concepts and intellectual abilities to utilize, comprehend, create and share educational solutions mediated through technologies.
\end{abstract}

Key words: technological fluency, tutors, virtual environments. 


\section{Introdução}

A integração de tecnologias da informação e comunicação nas atividades quotidianas altera e amplia as relações humanas. A evolução e a expansão das tecnologias estão cada vez mais intensas, incidindo diretamente no campo educacional e possibilitando novas formas de comunicação e socialização de saberes. As informações fluem com rapidez, em rede, com acesso e compartilhamento cada vez mais exigente em termos de interatividade.

Essas transformações tecnológicas demandam novas competências em relação ao processo educacional e à produção de conhecimentos. Segundo Lévy (1999, p. 126), a cultura das redes se estabelece na articulação entre os "princípios de interconexão, as comunidades virtuais e a inteligência coletiva". As redes ampliam e viabilizam o acesso rápido a conteúdos em formatos diversos.

Nesse contexto, para que se desenvolva a mediação pedagógica do tutor em ambientes virtuais, a fluência tecnológica se torna extremamente importante para promover a interação com os estudantes, proporcionando-lhes oportunidades de construção de conhecimento. $\mathrm{O}$ aprimoramento tecnológico gera remodelações pedagógicas e curriculares em virtude das possibilidades concretas de interação e interatividade, na qual há necessidade de selecionar informações e transformá-las em conhecimento.

O tutor, mediador que compartilha com o professor a responsabilidade pela prática dialógica nos ambientes virtuais, promove interação de modo a atingir os objetivos da formação e, principalmente, orienta o desenvolvimento da capacidade de análise e resolução de problemas. Nesse sentido, a fluência tecnológica do tutor se torna requisito para mediação que desafia os estudantes a procurarem se apropriar sempre mais das ferramentas tecnológicas, a fim de produzir e problematizar informações, e não somente absorvê-las.

Os ambientes virtuais permitem a integração de diferentes recursos e atividades, com interfaces de comunicação síncronas e assíncronas que possibilitam a criação de situações de aprendizagens diversificadas, permitindo comunicação dialógica e problematização das situações de ensino-aprendizagem. Assim, possibilita-se a interatividade e a comunicação multidirecional, oferecendo subsídios para que os estudantes possam se comunicar e realizar as atividades no tempo, ritmo e espaço mais apropriados às condições e cronogramas de estudo.

Por isso, neste artigo, objetivamos analisar de que modo os tutores utilizam e compreendem as ferramentas recursos (disponibilização de conteúdos) e atividades de aprendizagem para potencializar a mediação pedagógica em ambientes virtuais. Pretendemos, assim, investigar o potencial de fluência dos tutores no que se refere à criação e ao compartilhamento de soluções utilizando as tecnologias educacionais.

\section{Tutoria}

A educação a distância acontece numa relação educativa mediada entre professor-tutor-estudante apoiados pelas tecnologias educacionais. Desse modo, a mediação do tutor se torna extremamente importante visto a necessidade de desenvolver competência em relação ao processo cognitivo dos estudantes.

Segundo Gonçalves (2007), a tutoria é definida como o conjunto de ações educativas que contribuem para desenvolver e potencializar as capacidades básicas dos estudantes, orientando-os, dirigindo-os, motivando-os, avaliando-os para que obtenham 
crescimento intelectual e autonomia. Percebemos que, dentre esses aspectos, destacamse valores e atitudes através dos quais o tutor, além da mediação pedagógica, contribui para formação de novas gerações inseridas num contexto social.

Ao acompanhar os alunos durante o processo de aprendizagem, monitorando-os permanentemente, o tutor contribui para o desenvolvimento de sua capacidade de organização dos estudos, das atividades e da própria aprendizagem. Ao verificar a participação e interação, consegue diagnosticar os avanços, esclarecendo e instigando o diálogo em torno da compreensão do conteúdo. Isso leva ao desenvolvimento de um processo não linear e mais investigativo, de tal modo que se valorize a interação e, consequentemente, a colaboração.

Considerando a especificidade do seu papel enquanto mediador do processo pedagógico:

(...) o tutor deve ser compreendido como um dos sujeitos que participa ativamente da prática pedagógica. Suas atividades desenvolvidas a distância e (ou) presencialmente devem contribuir para o desenvolvimento dos processos de ensino e de aprendizagem e para o acompanhamento e avaliação do projeto pedagógico (BRASIL, 2007, p. 21).

E, ainda, para que possa desenvolver sua função significativamente, é imprescindível o tutor ter o domínio do conteúdo. Além disso, é necessário dinamismo, visão crítica e global, capacidade para estimular a busca de conhecimento e a habilidade com as novas tecnologias de informação e comunicação (BRASIL, 2007, p. 22).

Nesse viés, a fluência tecnológica dos tutores é uma competência essencial enquanto possibilidade para análise regular do desenvolvimento das atividades propostas, do acesso aos recursos, da identificação de dificuldades individuais e/ou coletivas, propondo soluções. Ao utilizar os recursos educacionais para apoiar a comunicação, ampliar a interação, auxiliar o gerenciamento do tempo e dos estudos, mediar as discussões nos fóruns, mantendo registro e contato regular com os estudantes durante todo o curso, o tutor desenvolve sua função de mediação pedagógica e de apoio às atividades do professor de cada disciplina.

Os recursos e atividades de estudo em ambientes virtuais devem ser planejados considerando que o estudante se beneficia com as multi-interações entre o grupo. Diante disso, a ação do tutor pode mobilizar condutas colaborativas nos trabalhos em grupo, artigos escritos conjuntamente, discussões em torno do conteúdo, desenvolvendo a colaboração entre os sujeitos.

O desenvolvimento de atividades de estudo, mediadas por tecnologias educacionais, pode ajudar o estudante a se tornar autônomo. Com o apoio do tutor, a partir do diálogo e da proposição de alternativas e caminhos mais próximos a ele, o processo formativo é mais bem orientado pelos conteúdos curriculares essencialmente propostos pelas políticas públicas e pelos projetos pedagógicos.

Assim, a mediação implementada pelo tutor torna-se aspecto relevante para garantir interação entre os agentes envolvidos no curso (Philipsen et al., 2007). Esse é o elemento central destacado nos Referenciais de Qualidade (Brasil, 2007), que preveem modelos de tutoria que garantam interação no processo ensino-aprendizagem.

\section{Por que o tutor precisa desenvolver fluência tecnológica?}

No universo de atribuições mediadas pelas tecnologias, a literatura aponta a importância de conhecer, entender, saber articular e utilizar essas tecnologias 
adequadamente, o que pode ser compreendido no conceito fluência tecnológica. Segundo o Committee on Information Technology Literacy (1999), fluência é a capacidade de reformular conhecimentos, expressar-se criativamente e de forma adequada, a fim de produzir e gerar informação (em vez de simplesmente compreendêla).

Desse modo, construir conhecimento (fluência) em torno das tecnologias requer cada vez mais o aperfeiçoamento, desenvolvendo, ao longo das experiências vivenciadas, competências e habilidades que permitam saber utilizar as ferramentas de acordo com situações específicas. O Committee on Information Technology Literacy (1999) ressalta que

ser fluente é pessoal no sentido de que os indivíduos fluentes com tecnologias da informação avaliam, distinguem, aprendem e usam novas tecnologias da informação conforme apropriado para suas atividades pessoais e profissionais (p. 6-7, tradução própria).

Existem pessoas que buscam conhecer mais sobre as tecnologias, pois entendem a importância delas para a sua vida quotidiana. Existem outras que possuem uma compreensão limitada das ferramentas e não se sentem confiantes para utilizá-las. E ainda há aquelas que sabem da importância e dos benefícios oferecidos pelas tecnologias, mas não se sentem aptas a fazer uso delas ou não procuram aperfeiçoamento.

Destacamos que a fluência tecnológica consiste em um processo de aprendizagem ao longo da vida. Nesse processo, os indivíduos desenvolvem habilidades através de adaptações a mudanças, adquirindo, assim, novos conhecimentos e modos de aplicação de tecnologias. Dessa forma, ser fluente requer o desenvolvimento da capacidade de utilizar aplicativos, de saber explicar como e para qual finalidade utilizamos tais ferramentas, enfim, de aplicar as tecnologias em situações complexas tanto pessoais quanto sociais e profissionais (Committee on Information Technology Literacy , 1999). Tais capacidades podem ser mais bem compreendidas na figura 1 , que destaca as habilidades contemporâneas, conceitos fundamentais e capacidades intelectuais para utilizar, compreender, criar e compartilhar soluções educacionais mediadas pelas tecnologias. Essa figura foi elaborada com base nos conceitos de Committee on Information Technology Literacy (1999). 


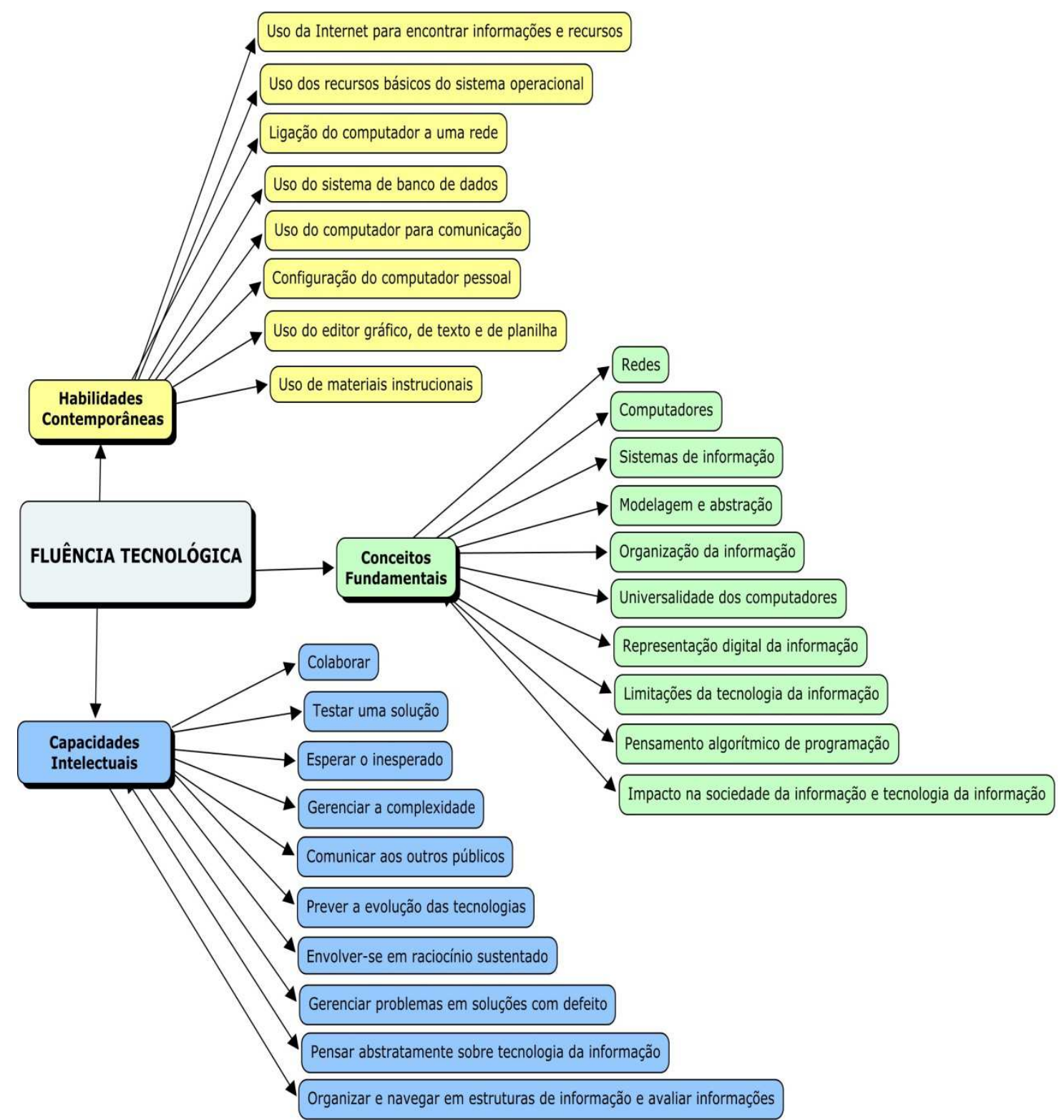

Figura 1 - Habilidades, capacidades e conceitos relacionados à fluência tecnológica.

Ao considerarmos que ser fluente é ser capaz de utilizar as tecnologias, desenvolver, compreender os conceitos básicos e estar sempre pronto a mudanças, problematizamos e pesquisamos a atuação dos tutores em ambientes virtuais:

- Os tutores possuem, de fato, a capacidade de utilizar as ferramentas dos ambientes virtuais para acompanhar/diagnosticar a aprendizagem dos estudantes (monitoramento) nas atividades propostas pelos professores?

- Os tutores compreendem e utilizam as ferramentas disponíveis nos ambientes virtuais para implementar suas funções?

- Os tutores utilizam, explicam e aplicam conceitos das tecnologias para desenvolver suas tarefas de acordo com os planos de trabalho de cada curso e/ou disciplina?

Ao desenvolvermos pesquisa no âmbito dessa preocupação temática (questões de pesquisa), amparamo-nos nos Referenciais de Qualidade para a Educação Superior a Distância (Brasil, 2007). Esse documento explicita que a interação, mediada por tecnologias, deve ser apoiada em um adequado sistema de tutoria. Parece que no 
contexto da educação a distância e dos ambientes virtuais, ainda não está muito claro o que significa "um adequado sistema de tutoria".

No contexto das pesquisas que realizamos (MALLMANN; SCHNEIDER, 2011), nas estratégias de análise detalhada das publicações científicas atuais sobre a temática, temos percebido que a definição de "um adequado sistema de tutoria" está cada vez mais vinculada ao desenvolvimento de fluência tecnológica, a fim de implementar monitoramento eletrônico em torno da interatividade, interação e colaboração (autoria e coautoria) essenciais para o processo ensino-aprendizagem em ambientes virtuais.

Ao monitorar e problematizar as atividades em ambientes virtuais, o tutor ajuda o estudante a buscar respostas e soluções. Esse monitoramento não se reduz à simples conferência dos relatórios de acesso dos estudantes, mas à utilização dos recursos educacionais para apoiar a comunicação, ampliar a interação, auxiliar no gerenciamento do tempo e dos estudos, mediar as discussões nos fóruns, mantendo registro e contato regular com os estudantes durante todo o curso. É dessa forma que o tutor desenvolve sua função de mediação pedagógica e de apoio às atividades do professor de cada disciplina.

Os recursos e atividades em ambientes virtuais devem ser planejados considerando que o estudante se beneficia com as interações e colaborações, a fim de estabelecer níveis mais complexos de flexibilidade cognitiva essencial na construção do conhecimento. Diante disso, a ação dos tutores pode mobilizar condutas investigativas nos trabalhos em grupo, escrita conjunta, discussões em torno do conteúdo, desenvolvendo a colaboração entre os sujeitos. Entretanto, um ambiente informatizado por si só não se constitui problematizador. Para ser realmente potencializador de práticas pedagógicas colaborativas e problematizadoras, é necessário que os tutores estejam preparados para explorar as ferramentas disponíveis nesses ambientes.

Quer dizer que os ambientes virtuais "por si sós, não são capazes de trazer contribuições para a área educacional e [...] eles são ineficientes se usados como o ingrediente mais importante do processo educativo, ou sem a reflexão humana" (Rezende, 2002, p.1). Por isso, seus recursos e atividades devem ser problematizados pelo tutor, conduzindo o estudante à busca de respostas, à tomada de posições, à criação de regras para implementar autonomia e aprendizagem colaborativa do início ao fim do curso. Ou seja, o apoio do tutor (fluente tecnológica e pedagogicamente) é essencial, já que isso orienta as ações dos estudantes e contribui para o desenvolvimento de habilidades que os levam a conquistar a autonomia.

Ao acompanhar os estudantes durante o processo de aprendizagem, monitorando-os permanentemente, (diagnóstico da aprendizagem) o tutor contribui para o desenvolvimento da capacidade de organização dos estudos, das atividades e da própria aprendizagem. Verificando a participação e interação, ele consegue diagnosticar os avanços, esclarecendo e instigando o diálogo em torno da compreensão do conteúdo. Desse modo, o tutor desenvolve estratégias que mobilizam condutas colaborativas entre os estudantes ao longo do processo ensino-aprendizagem, a partir dos recursos e atividades de estudo planejadas pelo professor.

\section{Estratégia Metodológica}

A pesquisa sobre a fluência tecnológica dos tutores em ambientes virtuais vem sendo implementada como pesquisa-ação por meio de observação participante e 
aplicação de um questionário tipo survey (BABBIE, 2001) aos tutores presenciais e a distância.

Elaboramos esse questionário com 25 questões de múltipla escolha. A coleta dos dados ocorreu no período compreendido entre março de 2011 e abril de 2012. Dos questionários encaminhados, tivemos retorno de 57 tutores. Considerando as questões éticas de pesquisa, os objetivos e a sua finalidade foram explicitados, deixando transparentes as intenções da pesquisa e a confidencialidade das informações.

Os resultados de pesquisa-ação foram analisados a partir de duas categorias eleitas com base no referencial teórico relacionado à fluência tecnológica dos tutores. Para tanto, amparamo-nos nos princípios da fluência tecnológica enfatizados pelo Committee on Information Technology Literacy (1999): habilidades contemporâneas, conceitos fundamentais e capacidades intelectuais.

Tal análise proporcionou um movimento analítico-avaliativo em relação à compreensão do tutor quanto à fluência tecnológica, considerando que a utilização e compreensão das ferramentas recursos e atividades nos ambientes virtuais é essencial para potencializar a mediação pedagógica.

\section{Resultados e Discussões}

Realizamos a análise apresentando os dados coletados a partir de observação participante e questionário tipo survey (BABBIE, 2001), implementado com tutores presenciais e a distância. A compilação dos dados foi realizada com 57 questionários respondidos, permitindo analisar e interpretar a relação entre a fluência tecnológica e as atribuições dos tutores. Para este trabalho, destacamos duas questões do questionário diretamente relacionadas com a fluência em tecnologias educacionais. A primeira questão relaciona a fluência tecnológica com a interatividade e a interação.

A interatividade, potencializada pela fluência tecnológica, relaciona-se com a ação do tutor em manipular as ferramentas do Moodle para saber onde, como, quando e para quê "clicar" a fim de ter acesso aos recursos e atividades de aprendizagem. Ao navegar na internet, ler uma mensagem eletrônica, utilizar editores de texto, preencher senhas, fazer download e upload de arquivos, o tutor implementa operações básicas que efetivam a interatividade.

A interação, entendida como uma ação mútua entre dois ou mais sujeitos que viabiliza a socialização, a obtenção de competências e habilidades, objetivando o ensino-aprendizagem ativo, efetiva-se através dos Recursos e Atividades. Proporciona o uso das interfaces de comunicação como potencializadoras de problematizações, questionamentos, confronto de ideias e soluções, reforçando, assim, o caráter participativo e formativo das atividades. Para tanto, é necessário que os tutores tenham fluência tecnológica em torno das tecnologias educacionais para que possam potencializar a interação.

Ao questionarmos os tutores sobre a necessidade de desenvolver fluência tecnológica para a potencialização da interação e interatividade, verificamos que a grande maioria $(80,70 \%)$ concorda plenamente que a fluência tecnológica é importante. Entretanto, 5,26 e 1,75\% dos tutores ainda discorda completamente ou em parte, conforme demonstra a figura 2 : 


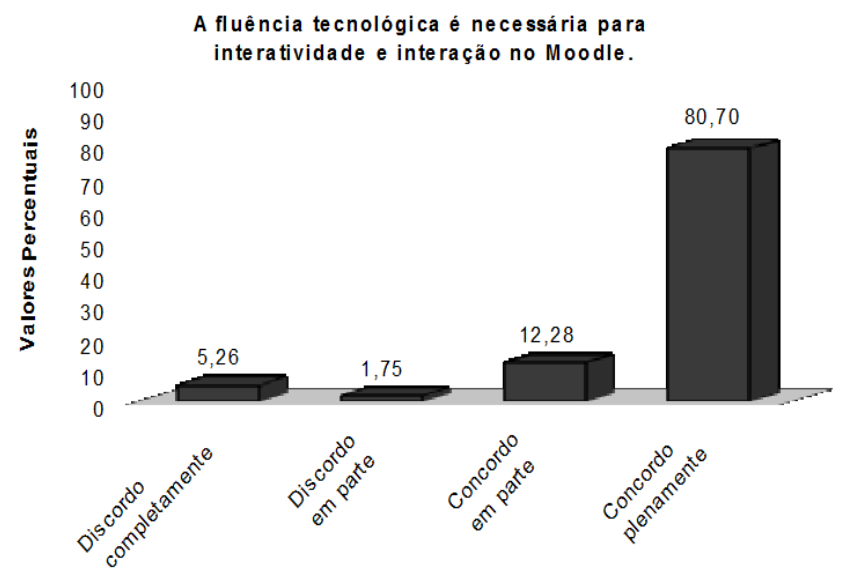

Figura 2 - Desenvolvimento de fluência tecnológica

Tais resultados evidenciam algumas hipóteses: os tutores não realizam todas as ações que lhe são cabíveis; os tutores não compreendem o que são exatamente fluência tecnológica, interação e interatividade.

A primeira hipótese foi considerada tendo em vista que os tutores podem não estar realizando todas as ações que lhe são atribuídas. Ou seja, desenvolvem ações que não necessitam de muita fluência com as tecnologias, como responder mensagens, por exemplo. A segunda hipótese é vista como uma possibilidade, já que no Brasil ainda há poucos estudos sobre tecnologias educacionais, como os ambientes virtuais que se baseiam no conceito fluência tecnológica. Quer dizer que é um tema pouco explorado nas políticas públicas e mesmo nos processos de capacitações institucionais. Por isso, é bem possível que muitos tutores ainda não conheçam de fato esse conceito, interferindo na relação que desenvolvem com a necessidade de interação e interatividade.

A segunda questão analisada aqui relaciona a fluência tecnológica com as dificuldades dos tutores em relação às ferramentas Recursos e Atividades no ambiente específico que é o Moodle. O tutor fluente nos recursos educacionais tem condições de ajudar os estudantes a fazer uso das ferramentas de forma segura, eficaz e flexível para apreensão e compreensão das situações-limite, desenvolvendo a capacidade crítica em torno das atividades propostas pelo professor.

Dos tutores questionados, 35,09\% disseram não apresentar dificuldades com as ferramentas do Moodle. Essa compreensão das ferramentas educacionais viabiliza a exploração e implementação das ações diante de situações-limite inesperadas, adaptando conceitos e ferramentas como solução alternativa.

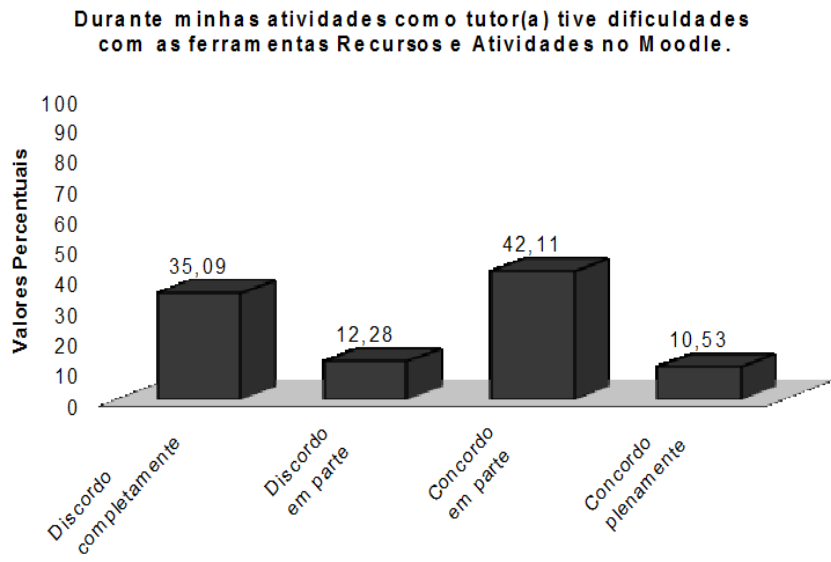

Figura 3 - Dificuldades com relação às ferramentas recursos e atividades no Moodle 
Quanto maior a compreensão do tutor em relação às ferramentas, maior será seu acesso aos benefícios que ela oferece. Os $10,53 \%$ dos tutores que afirmaram terem tido dificuldade e os demais 54,39\% que afirmaram terem apresentado algum tipo de dificuldade possivelmente não conseguiram desenvolver os três tipos de conhecimento que perpassam a fluência: capacidades intelectuais, habilidades e o conhecimento conceitual.

A capacidade intelectual relaciona-se com a ação do tutor em aplicar as especificidades dos recursos educacionais, compreendendo as consequências de fazê-lo. A habilidade é a capacidade de detectar, diagnosticar e corrigir problemas e falhas nas ferramentas propostas. Aliado a isso, a capacidade intelectual para a proficiência adicional, ou seja, compreensão dos conceitos que justificam o desenvolvimento da ferramenta e sua implementação.

Esses conhecimentos viabilizam a capacidade de planejar um caminho, criar uma solução, integrar diferentes possibilidades, responder a interações inesperadas e diagnosticar o que é necessário em determinada tarefa. Fluência tecnológica que incide diretamente nas atribuições do tutor, pois a interatividade pode facilitar e alterar a natureza da interação e, por sua vez, promover flexibilidade cognitiva.

As dificuldades em relação às ferramentas são minimizadas quando o tutor procura, avalia e transita por todas as informações, experienciando formas diferentes de realizar a mediação. O tutor precisa ser capaz de utilizar as ferramentas tecnológicas, exercitando o monitoramento tanto dos recursos como das atividades, diagnosticando avanços e desafios com relação a conceitos e conteúdos relacionados ao curso, auxiliando o professor na implementação e avaliação das atividades. Para isso, precisa buscar oportunidades para aprender mais sobre as ferramentas de recursos e de atividades nos ambientes virtuais.

\section{Conclusões}

A partir dos resultados de pesquisa, analisamos como os tutores utilizam e compreendem as ferramentas recursos e atividades de aprendizagem para potencializar a mediação pedagógica em ambientes virtuais. Tal preocupação temática tem contribuído com os tutores atuantes na reflexão acerca da sua concepção em relação à fluência tecnológica, problematizando o entendimento que eles possuem sobre as implicações da fluência no desenvolvimento de suas funções de tutoria. Isso proporciona a análise da prática e construção teórico/conceitual nas áreas e subáreas às quais se vincula a temática.

Verificamos, desse modo, que a fluência tecnológica apresenta relação direta com a implementação das atribuições dos tutores. Por conseguinte, é fundamental que os tutores desenvolvam fluência tanto em tarefas individuais como em produções colaborativas (autoria e coautoria), que permitem interação e problematização. As dificuldades com relação às ferramentas incidem sobre a mediação. Isso implica que a fluência potencializa as problematizações dos materiais de ensino-aprendizagem e mediação das situações-limite das atividades de aprendizagem, por parte do tutor. Quer dizer que desenvolver interação e interatividade através das ferramentas dos ambientes virtuais necessita de conhecimento e trânsito por elas para levar os estudantes à compreensão científico-tecnológica que é própria do conhecimento escolar.

Nesse caso, algumas das dificuldades apresentadas pelos tutores podem ser em decorrência de pouco trânsito pelas ferramentas e pouca pesquisa sobre as suas potencialidades. Isto é, alguns tutores ainda não são capazes de utilizar as tecnologias, 
como os ambientes virtuais, com confiança e adequadamente (habilidades contemporâneas, conceitos fundamentais e capacidades intelectuais), compreendendo pouco os conceitos básicos inerentes a elas.

Os dados obtidos ao longo da pesquisa indicam, por conseguinte, que desenvolver capacidades intelectuais, habilidades e o conhecimento conceitual (fluência tecnológica) é primordial para que o tutor tenha condições mínimas de implementar sua prática, formulando conhecimentos e compreendendo o que é possível criar com as tecnologias, modificando, ampliando ideias e compartilhando soluções.

\section{Referências Bibliográficas}

BABBIE, E. Métodos de Pesquisas de Survey. Belo Horizonte: Editora UFMG, 2001.

BRASIL. Ministério da Educação. Secretaria de Educação a Distância. Referenciais de qualidade para educação superior a distância. 2007. Disponível em: <http://portal.mec.gov.br/seed/indexar?option=com_content\&task=view\&id=248\&Item id=426> Acesso em: 26 abril. 2012.

COMMITTEE ON INFORMATION TECHNOLOGY LITERACY, NATIONAL RESEARCH COUNCIL. Being Fluent with Information Technology, 1999. Disponível em: <http://www.nap.edu/catalog/6482.html>. Acesso em: 20 jan. 2012.

GONÇALVES, L.M. Tutoria em EaD: com a palavra tutores e alunos. In:VII Encontro Internacional Virtual Educa Brasil, 2007, São José dos Campos.

LÉVY, Pierre. Cibercultura. Editora 34, São Paulo, 1999.

MALLMANN, E. M. ; SCHNEIDER, D. R. . Tutoria em Educação a Distância: indicadores para Políticas Públicas. In: $17^{\circ}$ Congresso Internacional ABED de Educação a Distância, Manaus : ABED, 2011.

PHILIPSEN, T; AFONSO, R.F.S.; DANDOLINI, G. A; SOUZA, J. A., O sistema detutoria no CLMD. In: RENOTE - Revista Novas Tecnologias na Educação. V.4 No 2,Dezembro, 2006. Disponível em: <http://seer.ufrgs.br/renote/article/view/14299/8216>. Acesso em 10 de maio de 2012.

REZENDE, F. As novas tecnologias na prática pedagógica sob a perspectiva construtivista. Ensaio - Pesquisa em Educação em Ciências. Belo Horizonte, v. 2, n. 1, 2002. Disponível em: 〈http://www.fae.ufmg.br/ensaio/v2_n1/flavia.PDF>. Acesso em: 20 abr. 2012. 